\title{
Dyspnea, depression and health related quality of life in pulmonary arterial hypertension patients
}

\author{
Arunabh Talwar ${ }^{1,2, *}$, Sonu Sahni', ${ }^{1,2}$ Eun Ji Kim³ ${ }^{3}$, Sameer Verma ${ }^{1,2}$, Nina Kohn² \\ ${ }^{1}$ North Shore-Long Island Jewish Health System, Department of Pulmonary, Critical Care and Sleep Medicine, New Hyde Park, NY, USA \\ ${ }^{2}$ Feinstein Institute for Medical Research, Manhasset, NY, USA \\ ${ }^{3}$ North Shore-Long Island Jewish Health System, Department of Medicine, Manhasset, NY, USA
}

\begin{abstract}
Pulmonary arterial hypertension (PAH) is a rare and devastating disease which is characterized by worsening dyspnea and exercise tolerance. These patients are often found to have concomitant, depression, anxiety and impaired health-related quality of life (HROOL). The interrelationship of dyspnea, depression and HROOL in these patients is not well studied. Retrospective analysis was performed on $46 \mathrm{PAH}$ patients (mean age 51.73). Patients completed Medical Outcomes Study Short Form 36 V2 (SF-36) to measure HROOL, Modified Medical Research Council (mMRC) Dyspnea Scale and Zung Depression Scale (ZDS). Physical Health Composite Scores (PCS) and Mental Health Composite Scores (MCS) were derived from SF-36. Spearman's correlation was computed to determine degree of correlation between pairs of scales. 46 patients (12 males, 34 females; median age 51.4 yr) with confirmed

PAH were considered for the study of which 36 patients $(9$ males, $27 \mathrm{fe}$ -
\end{abstract}

\section{INTRODUCTION}

Pulmonary hypertension (PHTN) is a rare and devastating disease characterized by progressive increases in pulmonary arterial pressure and pulmonary vascular resistance which eventually leads to right ventricular failure and death (Farber and Loscalzo, 2004). It may due to various etiologies such as left heart disease, parenchymal lung disease leading to hypoxia, chronic thromboembolic disease, hematologic disorders or it may be idiopathic in nature. The World Health Organization (WHO) has created a classification system for pulmonary hypertension based on common clinical features (Simonneau et al., 2013). Pulmonary arterial hypertension (PAH), considered WHO Group I PHTN, is often considered idiopathic or may due to connective tissue disease, HIV males, median age $50.1 \mathrm{yr}$ ), were eligible for further analysis. MMRC Dyspnea Scale Score was 1.0 (01 to 03:1.0 to 2.0). Median MCS was 52.1 (01 to 03:41.7 to 57.1) and PCS was 37.9 (01 to $03: 30.7$ to 49.6). There was a significant negative correlation between dyspnea and PCS $(r=-0.660, P<0.0001)$ and MCS $(r=-0.342, P<0.0411)$. The ZDS was available for 17 of these patients; their median score was 42.0 (01 to $03: 33.0$ to 46.0). There was a significant correlation between the ZDS and PCS ( $r$ $=-0.578, P<0.0150$,$) MCS (r=-0.752, P<0.0005)$. Patients with PAH suffer from diminished HROOL correlating with their dyspnea and underlying depression.

Keywords: Pulmonary arterial hypertension, Dyspnea, Depression, Health related quality of life, Patient reported outcomes, Pulmonary hypertension
${ }^{*}$ Corresponding author: Arunabh Talwar

North Shore-Long Island Jewish Health System, Department of Pulmonary, Critical

Care and Sleep Medicine, 410 Lakeville Rd. Suite 107 New Hyde Park, NY 11040, USA

Tel: +1-516 465-5400, Fax: +1-516-465-5454, E-mail: arunabh@nshs.edu

Received: August 20, 2015 / Accepted: October 1, 2015 infection, congenital heart disease or heritable in nature. Symptomatically PAH patients are characterized by increasing shortness of breath and worsening exercise tolerance.

Due to the progressive nature of this condition and its debilitations, patients with PAH have been often found to have concomitant, depression, anxiety and severely impaired health-related quality of life (HRQOL) (Löwe et al., 2004; Taichman et al., 2005; Verma et al., 2014). It is also known that dyspnea, a major component of this disease, is independently related to depressive symptoms (Kellner et al., 1992). The effects and relationship of dyspnea, depression and HRQOL in these patients is not well studied but it is very important, as it may shine a light on psychosomatic domains of this disease which sets the basis of this study. We decided to study the relationship of patient self report dys- 
pnea, depression and HRQOL in patients with WHO Group I PAH.

\section{MATERIALS AND METHODS}

\section{Patients}

Retrospective chart analysis was performed on 46 patients with a diagnosis of pulmonary hypertension at the North Shore - Long Island Jewish Health System who were being considered for pulmonary rehabilitation. Pulmonary hypertension was defined in accordance to the ACCF/AHA guidelines (McLaughlin et al., 2009). Pulmonary arterial hypertension (PAH) is defined hemodynamically as a mean pulmonary artery pressure (mPAP) greater than or equal $25 \mathrm{mmHg}$ and a pulmonary capillary wedge pressure (PCWP) less than or equal to $15 \mathrm{mmHg}$ which must be confirmed by right heart catheterization (RHC) (Badesch et al., 2009). As a part of their pre-pulmonary rehabilitation screening patients were asked to complete a series of questionnaires including the MMRC Dyspnea Scale, Zung Depression Scale and Medical Outcomes Study SF-36 V2 Health Survey to measure generic HRQOL. Physical component scores (PCS) and mental component scores (MCS) were derived from SF36V2. Patients who were found to have WHO Group I pulmonary arterial hypertension and had completed the MMRC Dyspnea Scale and the SF-36 were included in this the study.Data was analyzed using SAS (Cary, NC USA). The Spearman correlation coefficient was computed to determine the degree of correlation between each pair of scales. Summary statistics are reported as medians and 25th percentile (Q1) to 75th percentile (Q3). Institutional Review Board approval was obtained for this study.

\section{Measuring dyspnea, depression and health related quality of life}

To determine different aspects of psychosomatic health quantitative measurements of dyspnea, depression and health related quality of life must be determined. Quantification of such data makes it feasible to determine their correlation, as it may not be well known. In the setting of pulmonary arterial hypertension, a chronic debilitating disease, dyspnea, depression, and quality of life are often intertwined.

\section{Dyspnea}

As dyspnea is one of the most common symptoms across cardiovascular and pulmonary medicine, defining its severity is important.Many scales have been identified to measure dyspnea (Cri- safulli and Clini, 2010) but the Modified Medical Research Council Dyspnoea Scale (MMRC Dyspnoea Scale) has already previously been used to categorize disability in COPD (Cazzola et al., 2008). As this is a patient reported scale, patients are asked about their perceived breathlessness and responses are then classified according to how they perceive their dyspnea. The MMRC dyspnea scale is a questionnaire that consists of five statements about perceived breathlessness: grade 0 , "I only get breathless with strenuous exercise"; grade 1, "I get short of breath when hurrying on the level or up a slight hill"; grade 2, "I walk slower than people of the same age on the level because of breathlessness or have to stop for breath when walking at my own pace on the level"; grade 3, "I stop for breath after walking 100 yards or after a few minutes on the level"; grade 4, "I am too breathless to leave the house" or "I am breathless when dressing". The MMRC correlates well with other measures of dyspnea that have been used in the pulmonary setting as well (Wilson et al., 1997).

\section{Depression}

Depression is a common entity amongst PAH patients (Verma et al., 2014) and to define its severity is important as its presence may impact dyspnea and HRQOL. Many depression scales have been developed to measure depression in a primary care setting (Williams et al., 2002), however the Zung Depression Scale (ZDS) has been found to be quick, simple and easy to administer to patients (Shafer, 2006). The ZDS is a self-reporting 20-item instrument used to promptly assess severity of depression in patients, with half of the items stated negatively and the other half stated positively (Zung, 1965). Each item score range is from 1 through 4. A total score of 50 and greater indicates some severity of depression. The test is quick, simple and easy to administer to patients. It is primarily used in clinical research to monitor treatment (Zung, 1965).

\section{Health related quality of life (HRQOL)}

Health-related quality of life is defined by the Center for Disease Control as an assessment of how an individual's well-being is being affected over time by a disease, disability, or disorder. Measurement of HRQOL in the setting of PAH has been documented (Löwe et al., 2004). To assess HRQOL in our patients the SF-36 Health Survey v2 (Medical Outcomes Trust, Boston, MA, USA) was used as it is a generic measure of health related quality of life versus specific for disease, gender, age or treatment group (Ware, 2000). The benefit of using the SF-36 is that it is comprised of two sub components, a mental component summary (MCS) and a 
physical component summary (PCS). The PCS is comprised of 4 subsets: Physical Functioning, Role-Physical, Bodily Pain and General health. He MCS is comprised of 4 subsets as well: Vitality, Social Functioning, Role-Emotional and Mental Health. Three scales, (Physical Functioning, Role-Physical, and Bodily Pain) correlate most highly with the physical component and contribute most to the scoring of the PCS measure (Tucker et al., 2010).

Table 1. Patient characteristics and study results

\begin{tabular}{lc}
\hline Age $(y r) n=36$ & $50.01 \pm 13.48$ \\
Sex (male/female) & $9(25.0 \%) / 27(75.0 \%)$ \\
mMRC Dyspnea Scale Score $(n=36)$ & $1.36 \pm 1.15$ \\
SF-36 Health Survey MCS $(n=36)$ & $48.99 \pm 11.74$ \\
SF-36 Health Survey PCS $(n=36)$ & $39.53 \pm 10.95$ \\
Zung Depression Scale $(n=17)$ & $40.35 \pm 9.00$ \\
\hline
\end{tabular}

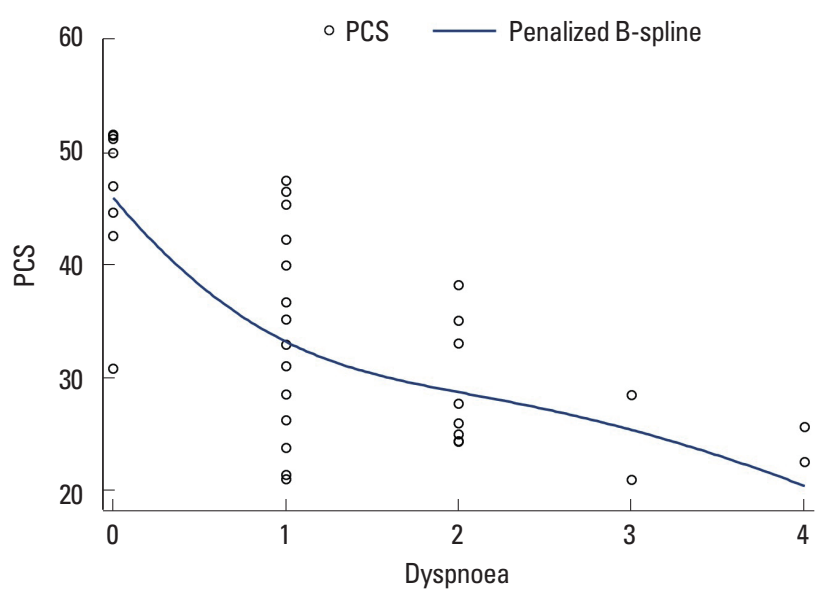

Fig. 1. The relationship between component scores of the SF-36 Scale (PCS).

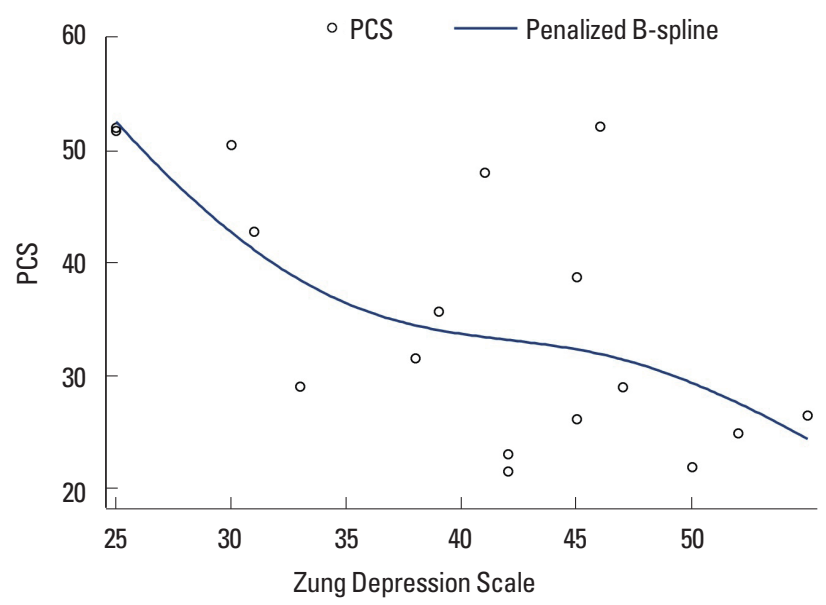

Fig. 3. The relationship between Zung Depression Scale and SF-36 component scores (PCS).
Whilst the mental component correlates most highly with the Mental Health, Role-Emotional, and Social Functioning scales, which contribute most to the scoring of the MCS measure (Tucker et al., 2010). Normal score for the SF-36 are based on a 0-100 scale with norm-based scoring of the 8 subscales with 50 being the mean. Expected scores for PCS are 20-58 and 17-62 for MCS with lower score correlating with reduced physical and mental quality of life (Ware, 2000).

\section{RESULTS}

46 patients (12 males, 34 females; median age $51.4 \mathrm{yr}$ ) with confirmed PAH (WHO Group I PHTN) on review of right heart catheterization data were considered for the study. Ten of these patients were missing data on either the MMRC Dyspnea Scale, or

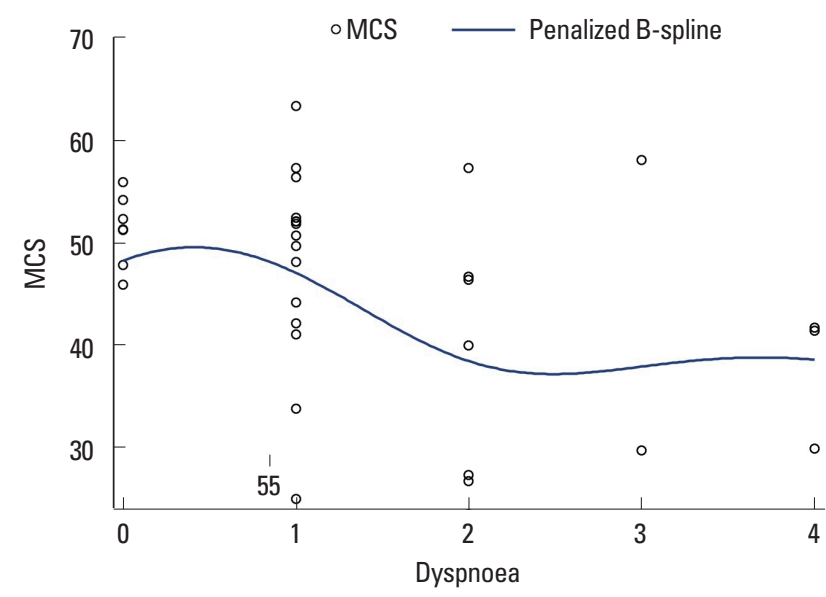

Fig. 2. The relationship between component scores of the SF-36 Scale (MCS).

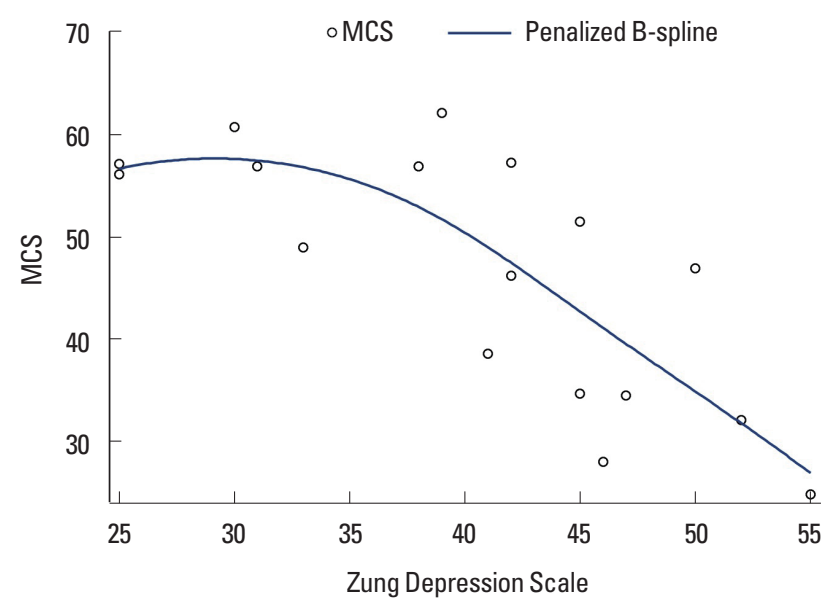

Fig. 4. The relationship between Zung Depression Scale and SF-36 component scores (MCS). 
Table 2. Summary of correlation between dyspnea, depression and HRQOL scale

\begin{tabular}{lcccc} 
& $\begin{array}{c}\text { mMRC Dyspnea } \\
\text { Scale Score }(n=36)\end{array}$ & $\begin{array}{c}\text { SF-36 Health } \\
\text { Survey MCS }(n=36)\end{array}$ & $\begin{array}{c}\text { SF-36 Health } \\
\text { Survey PCS }(n=36)\end{array}$ & $\begin{array}{c}\text { Zung Depression } \\
\text { Scale }(n=17)\end{array}$ \\
\hline mMRC Dyspnea & - & $r=-0.342$ & $r=-0.660$ & $r=0.620$ \\
Scale Score $(n=36)$ & & $P<0.0411$ & $P<0.0001$ & NS \\
SF-36 Health & $r=-0.342$ & - & & $r<0.0079$ \\
Survey MCS $(n=36)$ & $P<0.0411$ & & -0.752 \\
SF-36 Health & $r=-0.660$ & & & $P<0.0005$ \\
Survey PCS $(n=36)$ & $P<0.0001$ & $r=-0.578$ & $P<0.0150$ \\
Zung Depression & $r=0.620$ & $r<0.752$ & $r=-0.578$ & - \\
Scale $(n=17)$ & $P<0.0079$ & $P<0.0005$ & $P<0.0150$ & \\
\hline
\end{tabular}

NS, Not statistically significant.

the SF-36 questionnaire, or both, and so were excluded from further analysis. Thirty-six patients ( 9 males, 27 females, median age $50.1 \mathrm{yr}$ ), were eligible for further analysis (Table 1). The self reported median dyspnea in this PAH Group was 1.0 (Q1 to Q3:1.0 to 2.0) according to the mMRC Dyspnea Scale Score. The median mental component score (MCS) was 52.1 (Q1 to Q3:41.7 to 57.1) and physical component scores (PCS) was 37.9 (Q1 to Q3: 30.7 to 49.6). There was a significant negative correlation between dyspnea and PCS $(r=-0.660, P<0.0001)$ and between dyspnea and MCS $(r=-0.342, P<0.0411)$ (Fig. 1 and 2). The Zung Depression Scale was available for 17 of these patients; their median score was 42.0 (Q1 to Q3: 33.0 to 46.0). There was a significant correlation between the Zung depression scale and PCS ( $\mathrm{r}=$ $-0.578, P<0.0150)$ and between Zung depression scale and MCS $(\mathrm{r}=-0.752, P<0.0005)$ (Fig. 3 and 4$)$ indicating that in this cohort as perceived dyspnea increases patient self reported depression scores also increase. All data has been summarized (Table 2).

\section{DISCUSSION}

Health-related quality of life is defined as an individual's well-being as being affected over time by a disease, disability, or disorder. The definition of HRQOL can be portrayed as many factors but it is, debilitating, disease specific symptoms that affect patients view of HRQOL the most. Our retrospective study shows the relationship between disease specific symptoms, in this case dyspnea and its relationship with depression and HRQOL. Patient self reporting of dyspnea revealed that our cohort of $\mathrm{PAH}$ patients on average get dyspneic on exertion with a MMRC score of 1 which relates to "I get short of breath when hurrying on the level or up a slight hill". This explanation is somewhat expected as these patients suffer from a purely vascular disease while lung parenchyma stays intact. The pathogenesis of pulmonary hyper- tension is multifactorial and is characterized by abnormalities initiating in the small arteries of the pulmonary vasculature, including enhanced cell proliferation and reduced apoptosis, endothelial dysfunction, thrombosis in situ, inflammation, and plexiform arteriopathy, leading to vascular remodeling and excessive vasoconstriction (McLaughlin et al., 2009). In the setting of PAH these changes cause resistance for the blood flowing through the pulmonary arteries leading to increased pulmonary artery pressures and increased pulmonary vascular resistance pressures eventually leading to right heart failure due to increased after load, decreased contractility, and reduced cardiac output (Waxman, 2012). This combination of reduced cardiac output and increased pulmonary vascular resistance creates a situation where exertion causes dyspnea and negatively affects HRQOL.

HRQOL is a measure of overall well being and it is affected by both mental and physical components (Ware, 2000). It has been reported before that when dyspnea is one of the presenting factors in such conditions such as congestive heart failure it results in mental and cognitive dysfunction (Pressler et al., 2010) for which mechanisms are still unknown. The use of the SF-36 health survey has been validated and demonstrated diminished HRQOL in other pulmonary disease as well such as COPD and IPF (Mahler and Mackowiak, 1995; Martinez et al., 2000) where dyspnea is the primary symptom. Quantitative measurement of HRQOL is heavily dependent on patient reported questionnaires and in the field of PAH the use of the SF-36 questionnaire is limited to a few studies (Chua et al., 2006; Taichman et al., 2005; Zlupko et al., 2008). More recently in a subgroup of patients PAH due to congenital heart disease it was found that a decrease in physical aspects of HRQOL may be a determinant of mortality (Blok et al., 2015).

The SF-36 Health Survey is a 36 question assessment tool which yields an eight scale profile scores as well as a composite 
physical health summary (PCS) and mental health summary (MSC) (Ware, 2000). Of great interest in our study is that patients with pulmonary arterial hypertension suffer from a slightly diminished mental and physical quality of life score as studied by the SF-36. The median mental component score (MCS) in WHO Group I PAH patient was 52.1 (Q1 to Q3:41.76 to 57.1; mean: 49.0 \pm 11.7$)$ and physical component scores (PCS) was 37.9 (Q1 to Q3:30.7 to 49.6; mean: 39.5 \pm 11.0 ). Though the MCS score was lightly diminished from the defined normal mean (Ware, 2000), PCS scores were markedly decreased. This may be in due in part to the fact that these patients face dyspnea on exertion or furthermore the trepidation that comes with physical activity in this specific population. We further evaluated the effect of dyspnea on health related quality of life. It was found that as self reported patient dyspnea, according to the MMRC Dyspnea Scale Score, increased, MCS decrease. There was a significant negative correlation between the MMRC Dyspnea Scale Score and MCS $(r=-0.342, P<0.0411)$ and between dyspnea and PCS scores $(r=-$ $0.660, P<0.0001)$. Taichman et al., have reported that worsening function correlates with a reduced health related quality of life (Taichman et al., 2005). Our study demonstrated that patient self reported dyspnea also negatively correlates with a reduced mental and physical quality of life. This is an important finding as patient reported outcomes are more insightful in to how the patient feels rather than quantitative measurements obtained in overall disease severity assessment. This is especially important in a disease such as PAH where disease severity does not always correlate with static values such as mean pulmonary arterial pressure or pulmonary vascular resistance (Cenedese et al., 2006).

In addition our study demonstrated a significant negative correlation between patient self reported depression as measured by the Zung Depression Scale and physical and mental component score of the SF-36 questionnaire [Zung depression scale and PCS $(\mathrm{r}=-0.578, P<0.0150, \mathrm{n}=17)$ and between Zung depression scale and MCS $(\mathrm{r}=-0.752, P<0.0005, \mathrm{n}=17)]$. To the best of our knowledge this is the first study of its kind that shows the impact that depression has on mental and physical health scores in the cohort of PAH patients.It is known that patients with PAH suffer from depression and anxiety (Löwe et al., 2004). Our study highlights the relationship between depression and its possible effects on the physical and mental components of HRQOL.

In general our study also highlights the importance of patient reported outcomes (PROs). Dyspnea, depression and HRQOL are often assessed with the use of questionnaires filled out by patients and their treatment is based on patient centered care. Medical re- search has traditionally focused on concrete, often quantitative biomedical outcomes rather than the qualitative,patient-centered outcomes such as fatigue, health related quality of life, and patient satisfaction (Laine and Davidoff, 1996). As our heath care system progresses to a more multidisciplinary approach greater attention needs to be placed on these PROs. PROs offer the advantage advantages by allowing healthcare providers to determine how the disease is affecting the patient in the inside and possible effects of treatment that may only be evident only to the patient. PROs are able to be quickly administered and provide and additional dimension to diagnosing and managing a disease such as $\mathrm{PAH}$. Although the Agency of Healthcare Research and Quality has made strong strides in the area of patient-centered research, the birth of the Patient-Centered Outcomes Research Institute propels us toward realizing the elusive goals of true patient centered care (Selby et al., 2012). Patient-centered outcomes research that focuses on HRQOL and its components can further enhance quality of care.

Though vasodialtory pharmaceutical options for WHO Group I PAH exist such as phosphodiesterase 5 (PDE-5) inhibitors, endothelin receptor antagonists (ERAs) or prostacyclin derivatives (Galiè et al., 2013), they focus more on hemodynamics and exercise tolerance. However there is evidence that non-pharmacological therapies such as pulmonary rehabilitation may address the debilitating symptoms of chronic lung disease such as PAH (Talwar et al., 2014).

It has been suggested by ATS guidelines that exercise and pulmonary rehabilitation may further address the qualitative aspects of this disease (Galiè et al., 2013; Sahni et al., 2015). This study opens up the argument that, as clinicians we should also be focusing efforts on addressing the psychosomatic aspects of this debilitating disease and how to manage these damaging symptoms. As pulmonary rehabilitation has been studied in this patient population with beneficial results (Sahni et al., 2015) it should be a adjunct therapy. Pulmonary rehabilitation has shown to decrease fatigue (Talwar et al., 2014), dyspnea (Reardon et al., 1994) and depression (Paz-Diaz et al., 2007). Furthermore pulmonary rehabilitation has been shown to increase health related quality of life (Grunig et al., 2012) and exercise tolerance in the form of Six Minute Walk Test (6MWT) (Chan et al., 2013).

Our study showed that patients with a chronic debilitating disease such as PAH are mentally and physically affected by their symptoms, in particular dyspnea.In addition it is important that underlying depression in PAH patient may be negatively affecting their HRQOL, which should be addressed.This is important as treatment guidelines should consider quality of life as possible 
therapeutic endpoint. Some of the limitations of this study are that it is retrospective in nature and a small sample size due to the rarity of this disease.In addition not all patients completely finished requested PROs which rendered the data unusable for analysis.

Patients with PAH suffer from diminished HRQOL which correlates with their self reported perceived dyspnea. In addition in PAH patients, as their self report depression score increased the more their mental and physical health related quality of life scores were affected. Healthcare providers need to appreciate the psychosocial impairment of patients with pulmonary hypertension. Pulmonary rehabilitation and cognitive behavioral interventions may benefit these patients. Further studies are necessary to evaluate and design interventions to improve HRQOL in these patients.

\section{ETHICAL APPROVAL}

As this was a retrospective chart review study this article does not contain any studies with human participants performed by any of the authors. Institutional Review Board approval was obtained for the retrospective chart analysis.

\section{CONFLICT OF INTEREST}

No potential conflict of interest relevant to this article was reported.

\section{REFERENCES}

Badesch DB, Champion HC, Sanchez MA, Hoeper MM, Loyd JE, Manes A, McGoon M, Naeije R, Olschewski H, Oudiz RJ, Torbicki A. Diagnosis and assessment of pulmonary arterial hypertension. J Am Coll Cardiol 2009;54:S55-66.

Blok IM, van Riel AC, Schuuring MJ, Duffels MG, Vis JC, van Dijk AP, Hoendermis ES, Mulder BJ, Bouma BJ. Decrease in quality of life predicts mortality in adult patients with pulmonary arterial hypertension due to congenital heart disease. Neth Heart J 2015;23:278-284.

Cazzola M, MacNee W, Martinez FJ, Rabe KF, Franciosi LG, Barnes PJ, Brusasco V, Burge PS, Calverley PM, Celli BR, Jones PW, Mahler DA, Make B, Miravitlles M, Page CP, Palange P, Parr D, Pistolesi M, Rennard SI, Rutten-van Mölken MP, Stockley R, Sullivan SD, Wedzicha JA, Wouters EF; American Thoracic Society; European Respiratory Society Task Force on outcomes of COPD. Outcomes for COPD pharmacological trials: from lung function to biomarkers. Eur Respir J 2008;31:416-469.
Cenedese E, Speich R, Dorschner L, Ulrich S, Maggiorini M, Jenni R, Fischler M. Measurement of quality of life in pulmonary hypertension and its significance. Eur Respir J 2006;28:808-815.

Chan L, Chin LM, Kennedy M, Woolstenhulme JG, Nathan SD, Weinstein AA, Connors G, Weir NA, Drinkard B, Lamberti J, Keyser RE. Benefits of intensive treadmill exercise training on cardiorespiratory function and quality of life in patients with pulmonary hypertension. Chest 2013;143:333-343.

Chua R, Keogh AM, Byth K, O'Loughlin A. Comparison and validation of three measures of quality of life in patients with pulmonary hypertension. Intern Med J 2006;36:705-710.

Crisafulli E, Clini EM. Measures of dyspnea in pulmonary rehabilitation. Multidiscip Respir Me. 2010;5:202-210.

Farber HW, LoscalzoJ. Pulmonary arterial hypertension. N Engl J Med 2004;351:1655-1665.

Galiè N, Corris PA, Frost A, Girgis RE, Granton J, Jing ZC, Klepetko W, McGoon MD, McLaughlin VV, Preston IR, Rubin LJ, Sandoval J, Seeger W, Keogh A. Updated treatment algorithm of pulmonary arterial hypertension. J Am Coll Cardiol 2013;62:D60-72.

Grunig E, Maier F, Ehlken N, Fischer C, Lichtblau M, Blank N, Fiehn C, Stöckl F, Prange F, Staehler G, Reichenberger F, Tiede H, Halank M, Seyfarth HJ,Wagner S, Nagel C. Exercise training in pulmonary arterial hypertension associated with connective tissue diseases. Arthritis Res Ther 2012;14:R148.

Kellner R, Samet J, Pathak D. Dyspnea, anxiety, and depression in chronic respiratory impairment. Gen Hosp Psychiatry 1992;14:20-28.

Laine C, Davidoff F.Patient-centered medicine. A professional evolution. JAMA 1996;275:152-156.

Löwe B, Grafe K, Ufer C, Kroenke K, Grunig E, Herzog W, Borst MM. Anxiety and depression in patients with pulmonary hypertension. Psychosom Med 2004;66:831-836.

Mahler, DA, Mackowiak, JI. Evaluation of the short-form 36-item questionnaire to measure health-related quality of life in patients with COPD. Chest 1995;107:1585-1589.

Martinez TY, Pereira CA, dos Santos ML, Ciconelli RM, Guimaraes SM, Martinez JA. Evaluation of the short-form 36-item questionnaire to measure health-related quality of life in patients with idiopathic pulmonary fibrosis. Chest 2000;117:1627-1632.

McLaughlin VV, Archer SL, Badesch DB, Barst RJ, Farber HW, Lindner JR, Mathier MA, McGoon MD, Park MH, Rosenson RS, Rubin LJ, Tapson VF, Varga J: American College of Cardiology Foundation Task Force on Expert Consensus Documents; American Heart Association; American College of Chest Physicians;American Thoracic Society, Inc; Pulmonary Hypertension Association.ACCF/AHA 2009 expert consensus document on pulmonary hypertension a report of the Ameri- 
can College of Cardiology Foundation Task Force on Expert Consensus Documents and the American Heart Association developed in collaboration with the American College of Chest Physicians; American Thoracic Society, Inc.; and the Pulmonary Hypertension Association. J Am Coll Cardiol 2009;53:1573-1619.

McLaughlin VV, Archer SL, Badesch DB, Barst RJ, Farber HW, Lindner JR, Mathier MA, McGoon MD, Park MH, Rosenson RS, Rubin LJ, Tapson VF, Varga J,Harrington RA, Anderson JL, Bates ER, Bridges CR, Eisenberg MJ, Ferrari VA, Grines CL, Hlatky MA, Jacobs AK, Kaul S, Lichtenberg RC, Lindner JR, Moliterno DJ, Mukherjee D, Pohost GM, Rosenson RS, Schofield RS, Shubrooks SJ, Stein JH, Tracy CM, Weitz HH, Wesley DJ; ACCF/AHA. ACCF/AHA 2009 expert consensus document on pulmonary hypertension: a report of the American College of Cardiology Foundation Task Force on Expert Consensus Documents and the American Heart Association: developed in collaboration with the American College of Chest Physicians, American Thoracic Society, Inc., and the Pulmonary Hypertension Association. Circulation 2009;119:2250-2294.

Paz-Diaz H, Montes de Oca M, Lopez JM, Celli BR. Pulmonary rehabilitation improves depression, anxiety, dyspnea and health status in patients with COPD. Am J Phys Med Rehabil 2007;86:30-36.

Pressler SJ, Subramanian U, Kareken D, Perkins SM, Gradus-Pizlo I, Sauvé MJ, Ding Y, Kim J, Sloan R, Jaynes H, Shaw RM.Cognitive deficits and health-related quality of life in chronic heart failure. J Cardiovasc Nurs 2010;25:189-198.

Reardon J, Awad E, Normandin E, Vale F, Clark B, ZuWallack RL. The effect of comprehensive outpatient pulmonary rehabilitation on dyspnea. Chest 1994;105:1046-1052.

Sahni S, Capozzi B, Iftikhar A, Sgouras V, Ojrzanowski M, Talwar A. Pulmonary rehabilitation and exercise in pulmonary arterial hypertension: An underutilized intervention. J Exerc Rehabil 2015;11:74-79.

Selby JV, Beal AC, Frank L. The Patient-Centered Outcomes Research Institute (PCORI) national priorities for research and initial research agenda. JAMA 2012;307:1583-1584.

Shafer AB. Meta-analysis of the factor structures of four depression ques- tionnaires: Beck, CES-D, Hamilton, and Zung. J Clin Psychol 2006;62: 123-146.

Simonneau G, Gatzoulis MA, Adatia I, Celermajer D, Denton C, Ghofrani A, Gomez Sanchez MA, Krishna Kumar R, Landzberg M, Machado RF, Olschewski H, Robbins IM, Souza R. Updated clinical classification of pulmonary hypertension. J Am Coll Cardiol 2013;62:D34-41.

Taichman DB, Shin J, Hud L, Archer-Chicko C, Kaplan S, Sager JS, Gallop R, Christie J, Hansen-Flaschen J, Palevsky H. Health-related quality of life in patients with pulmonary arterial hypertension. Respir Res 2005;6:92.

Talwar A, Sahni S, John S, Verma S, Cardenas-Garcia J, Kohn N. Effects of pulmonary rehabilitation on Fatigue Severity Scale in patients with lung disease. Pneumonol Alergol Pol 2014;82:534-540.

Tucker G, Adams R, Wilson D. New Australian population scoring coefficients for the old version of the SF-36 and SF-12 health status questionnaires. Qual Life Res 2010;19:1069-1076.

Verma S, Cardenas-Garcia J, Mohapatra PR, Talwar A. Depression in pulmonary arterial hypertension and interstitial lung diseases. N Am J Med Sci 2014;6:240-249.

Ware JE Jr. SF-36 health survey update. Spine (Phila Pa 1976) 2000;25:31303139.

Waxman $\mathrm{AB}$. Exercise physiology and pulmonary arterial hypertension. Prog Cardiovasc Dis 2012;55:172-179.

Williams JW Jr, Pignone M, Ramirez G, Perez Stellato C. Identifying depression in primary care: a literature synthesis of case-finding instruments. Gen Hosp Psychiatry 2002;24:225-237.

Wilson CB, Jones PW, O'Leary CJ, Cole PJ, Wilson R. Validation of the St. George's Respiratory Questionnaire in bronchiectasis. Am J Respir Crit Care Med 1997;156:536-541.

Zlupko M, Harhay MO, Gallop R, Shin J, Archer-Chicko C, Patel R, Palevsky HI, Taichman DB. Evaluation of disease-specific health-related quality of life in patients with pulmonary arterial hypertension. Respir Med 2008;102:1431-1438.

Zung WW. A self-rating depression scale. Arch Gen Psychiatry 1965;12:6370. 